\title{
The activity of indenylidene derivatives in olefin metathesis catalysts
}

\author{
Maria Voccia ${ }^{1}$, Steven P. Nolan ${ }^{* 2,3}$, Luigi Cavallo $^{*}$ and Albert Poater ${ }^{* 1}$
}

\section{Full Research Paper}

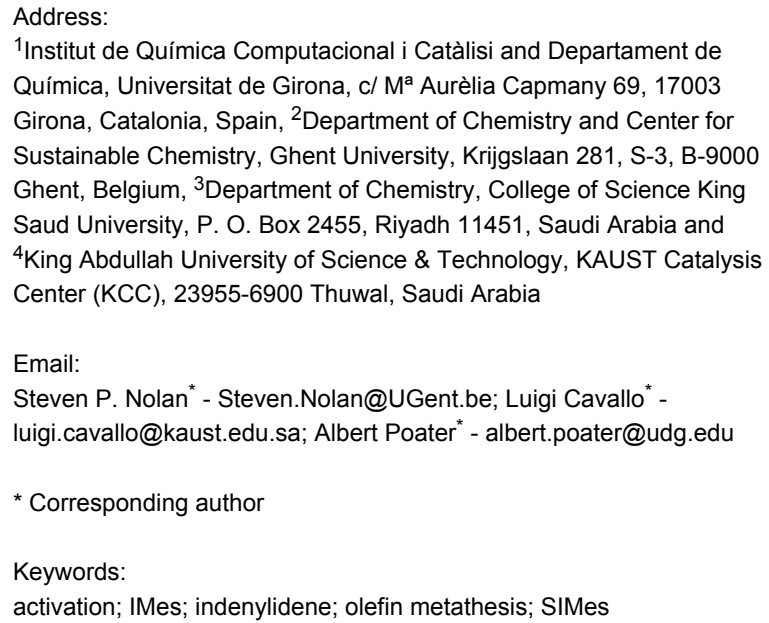

Beilstein J. Org. Chem. 2018, 14, 2956-2963. doi:10.3762/bjoc. 14.275

Received: 06 September 2018

Accepted: 15 November 2018

Published: 30 November 2018

This article is part of the thematic issue "Progress in metathesis chemistry III".

Guest Editors: K. Grela and A. Kajetanowicz

(c) 2018 Voccia et al.; licensee Beilstein-Institut. License and terms: see end of document.

\begin{abstract}
The first turnover event of an olefin metathesis reaction using a new family of homogenous Ru-based catalysts bearing modified indenylidene ligands has been investigated, using methoxyethylene as a substrate. The study is carried out by means of density functional theory (DFT). The indenylidene ligands are decorated with ortho-methyl and isopropyl groups at both ortho positions of their phenyl ring. DFT results highlight the more sterically demanding indenylidenes have to undergo a more exothermic first phosphine dissociation step. Overall, the study emphasises advantages of increased steric hindrance in promoting the phosphine release, and the relative stability of the corresponding metallacycle over classical ylidene ligands. Mayer bond orders and steric maps provide structural reasons for these effects, whereas NICS aromaticity and conceptual DFT confirm that the electronic parameters do not play a significant role.
\end{abstract}

\section{Introduction}

Olefin metathesis has been an intensely studied reaction due to its wide use [1], in industrial applications, especially in petrochemistry [2], i.e., the Phillips Triolefin (PTP) process or the Shell Higher Olefin Process (SHOP) [3,4]. Additionally, the olefin metathesis reaction has provided a useful tool in poly- merisation [5,6], as well as in the pharmaceutical industry in the formation of $\mathrm{C}=\mathrm{C}$ bonds. Early catalyst examples were illdefined entities and it is not until Grubbs [7] and Schrock [8] developed well-defined homogeneous catalysts that the area truly blossomed. Using a metal carbene complex as a catalyst, 
making use of the Chauvin mechanism, olefin metathesis consists of the redistribution of two carbon-carbon double bonds [9]. The metal and its ligand environment in both ruthenium and molybdenum systems appear to confer the right environment that allows a productive alkene metathesis [10,11]. Little productive reactivity has been uncovered using other metals [12-14]. Apart from the metal, ruthenium-based olefin metathesis has seen several changes during the last decades, modifying the existing commercial catalysts, playing mainly with the electronic characteristics of the ligands (usually two chlorides and an ylidene ligand) [15-17], whereas basically the sterics of the substituents on the N-heterocyclic carbene (NHC) ligand have remained unchanged [18]. Overall, any modification of the available catalysts has been performed in order to increase the stability of the catalyst without losing any of its activity $[19,20]$. Although most of the olefin metathesis catalysts are based on ruthenium [21,22], because these are more stable to oxygen and moisture [23] than their molybdenum counterparts, they display sensitivity to decomposition while in solution [24,25]. Understanding and/or the elimination of potential pathways that leads to catalyst decomposition is extremely important [26-28], since any knowledge obtained in this area can guide the catalyst design efforts [29-31].

We are interested in evaluating, by density functional theory (DFT) calculations, the difference in the activation step between complexes 1-6 in Scheme 1, whose reactivity and properties have been reported already (for 1 and 2) [24,32,33]. Predictive catalysis will be used here to generate and/or describe the activity in olefin metathesis of the new indenylidene derivatives. The phenyl substituent of the indenylidene is perpendicular to the indenyl moiety in the solid-state structure [34], as Nolan and co-workers first described in 1999 [35]. For complexes 3-6, where the phenyl ring is ortho-substituted, there might be present steric repulsion with the NHCs, which might in turn facilitate the departure of the indenyl ligand [36]. Apart from reducing decomposition [37,38], this steric pressure should lead to faster rates for the initiation step of the metathesis reaction. This hypothesis will be examined computationally in order to assist catalyst design efforts.

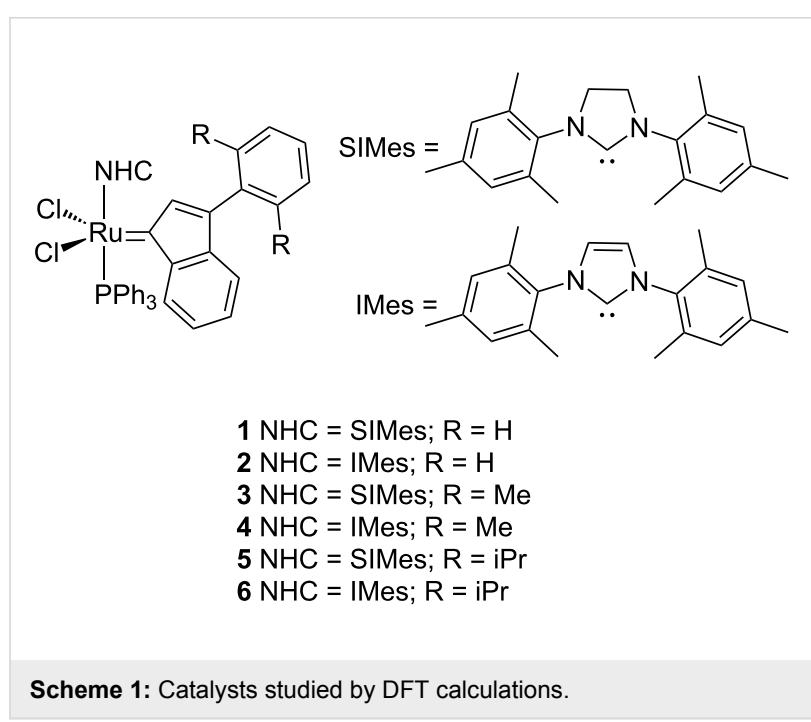

\section{Results and Discussion}

We have studied the initiation cycle involving the transformation of the indenylidene precatalysts into the active methylidene for a series of olefin metathesis relevant complexes 1-6, using methoxyethene as a substrate (Scheme 2). This substrate was selected in order to facilitate our analysis [39]. Computationally no significant differences exist by using ethene or methoxyethene [40,41]. The saturation of the backbone of the NHC has also been taken into account, thus considering either the SIMes (1,3-bis(2,4,6-trimethylphenyl)-4,5-dihydroimidazol2-ylidene) and the IMes (1,3-bis(2,4,6-trimethylphenyl)imidazol-2-ylidene) NHC ligands. The group trans to the NHC ligand is triphenylphosphine for all catalysts.

Table 1 includes the energy profiles for the substituted indenylidenes, bearing methyl or isopropyl groups at the ortho positions of the phenyl substituent, compared to the unsubstituted 1 and 2. Comparing IMes vs SIMes, the activation is about $1 \mathrm{kcal} / \mathrm{mol}$ more favoured for the unsaturated system $[42,43]$. The absolute difference of $1 \mathrm{kcal} / \mathrm{mol}$ is maintained throughout the mechanism, however, we must point out that the opening of the metallacycle requires only $0.6 \mathrm{kcal} / \mathrm{mol}$ for the SIMes system versus $1.7 \mathrm{kcal} / \mathrm{mol}$ for the unsaturated system.

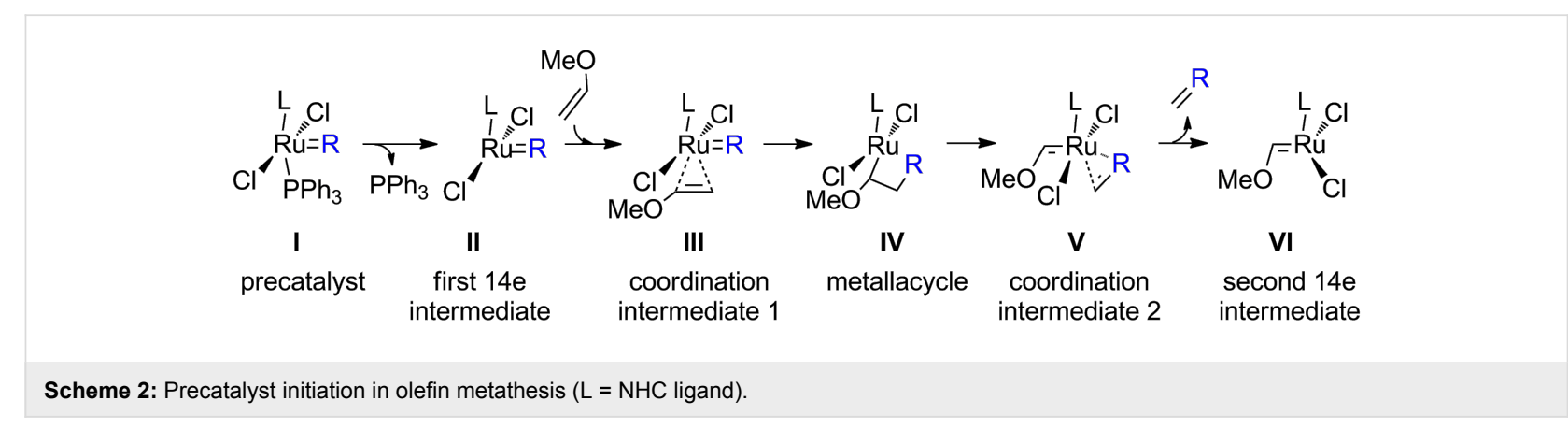


Table 1: Precatalyst initiation reaction pathway for catalysts 1-6 (M06/TZVP sdd//BP86/SVP sdd; Gibbs free energies in $\mathrm{kcal} / \mathrm{mol}$ ).

\begin{tabular}{lcccccc} 
& $\mathbf{1}$ & $\mathbf{2}$ & $\mathbf{3}$ & $\mathbf{4}$ & $\mathbf{5}$ & $\mathbf{6}$ \\
\hline I & 0.0 & 0.0 & 0.0 & 0.0 & 0.0 & 0.0 \\
I-II & 21.8 & 20.2 & 16.4 & $19.1^{\mathrm{a}}$ & 19.8 & 19.8 \\
II & 20.0 & 18.2 & 16.1 & 19.5 & 17.6 & 19.6 \\
II-III & 22.8 & 21.8 & 20.0 & 22.4 & 21.0 & 22.1 \\
III & 15.0 & 12.2 & 13.0 & 14.6 & 17.2 & 17.8 \\
III-IV & 22.1 & 21.1 & 19.0 & 20.1 & 17.8 & 19.3 \\
IV & 16.7 & 15.9 & 12.5 & 15.1 & 13.3 & 13.0 \\
IV-V & 17.3 & 17.6 & 13.7 & 15.8 & 15.6 & 16.2 \\
V & 7.0 & 3.7 & 2.0 & 3.5 & 2.9 & 2.9 \\
V-VI & 10.5 & 10.2 & 8.6 & 10.0 & 5.9 & 9.6 \\
VI & 8.1 & 7.0 & 3.8 & 5.4 & 4.3 & 5.0
\end{tabular}

aThe transition state is somewhat lower in energy than the next $14 \mathrm{e}$ species II once included the solvent effects.

The methyl and isopropyl-substituted indenylidene moieties reveal a different performance between the SIMes and the IMes congeners. When the saturated NHC is considered, the substitution reduces dramatically the barriers of the first two transition states. Then the cycle $\mathbf{I} \rightarrow \mathbf{V I}$ is more exothermic with the substituted systems. On the other hand, the unsaturated system does not reduce the energy barriers with the substituted indenylidene moieties, because of the rigidity of its backbone. And the same argument is valid for the entire catalytic system, which means that the substitution does not help to make the system significantly more exothermic than the saturated system, despite a slight stabilisation, especially for the second 14 e species, VI.

Overall, among the catalysts with substituted indenylidene catalysts, the one bearing a SIMes NHC ligand and methyl groups in the indenylidene moiety is the most promising, in agreement with the experimental hypothesis that the release of the indenylidene ligand is more facile in such a case.

The concerted transition state that circumvents the formation of the $14 \mathrm{e}$ intermediate II, i.e., I-III, is higher in energy than I-II and II-III by 3.6 and $4.3 \mathrm{kcal} / \mathrm{mol}$ for systems $\mathbf{3}$ and $\mathbf{5}$, compared to 1 , respectively. The unsaturated systems do not follow a concerted mechanism either, being $4.3 \mathrm{kcal} / \mathrm{mol}$ higher in energy for system 2 . Overall, for all substituted indenylidenes this concerted transition state $\mathbf{I}-\mathbf{I I I}$ is confirmed to be higher in energy.

The structural analysis included in Table 2 supports the fact that the substituted indenylidenes display similar characteristics whatever the substituents are on both ortho positions of the corresponding phenyl ring in catalysts $\mathbf{1}-\mathbf{6}$. For instance, the $\mathrm{Ru}=\mathrm{C}_{\text {ylidene }}$ bond changes by less than $0.008 \AA$, which is in perfect agreement with the insignificant changes in the Mayer Bond Order (MBO) results $[44,45]$. However, there is a clear

Table 2: Structural analysis for species I-III for catalysts 1-6 (in kcal/mol), including selected bond distances (d) in $\AA$ and Mayer Bond Orders (MBO).

\begin{tabular}{|c|c|c|c|c|c|c|}
\hline & 1 & 2 & 3 & 4 & 5 & 6 \\
\hline \multicolumn{7}{|c|}{$\mathrm{d}\left(\mathrm{Ru}=\mathrm{C}_{\text {ylidene }}\right)$} \\
\hline I & 1.882 & 1.882 & 1.883 & 1.883 & 1.886 & 1.885 \\
\hline II & 1.869 & 1.868 & 1.863 & 1.862 & 1.863 & 1.861 \\
\hline III & 1.888 & 1.885 & 1.885 & 1.883 & 1.885 & 1.884 \\
\hline \multicolumn{7}{|c|}{$\mathrm{MBO}\left(\mathrm{Ru}=\mathrm{C}_{\text {ylidene }}\right)$} \\
\hline I & 1.464 & 1.469 & 1.476 & 1.484 & 1.475 & 1.480 \\
\hline II & 1.444 & 1.446 & 1.467 & 1.470 & 1.465 & 1.471 \\
\hline III & 1.445 & 1.453 & 1.453 & 1.460 & 1.448 & 1.452 \\
\hline \multicolumn{7}{|c|}{$d(R u-P)$} \\
\hline I & 2.457 & 2.444 & 2.436 & 2.430 & 2.431 & 2.424 \\
\hline \multicolumn{7}{|c|}{$\mathrm{MBO}(\mathrm{Ru}-\mathrm{P})$} \\
\hline I & 0.540 & 0.560 & 0.585 & 0.592 & 0.600 & 0.611 \\
\hline \multicolumn{7}{|c|}{$d\left(R u-C_{N H C}\right)$} \\
\hline I & 2.071 & 2.089 & 2.087 & 2.103 & 2.093 & 2.111 \\
\hline II & 1.947 & 1.956 & 1.941 & 1.955 & 1.941 & 1.953 \\
\hline III & 2.020 & 1.885 & 2.019 & 1.883 & 2.014 & 2.029 \\
\hline \multicolumn{7}{|c|}{$\mathrm{MBO}\left(\mathrm{Ru}-\mathrm{C}_{\mathrm{NHC}}\right)$} \\
\hline I & 0.847 & 0.806 & 0.817 & 0.787 & 0.808 & 0.775 \\
\hline II & 1.199 & 1.151 & 1.211 & 1.160 & 1.212 & 1.162 \\
\hline III & 0.961 & 0.915 & 0.969 & 0.924 & 0.983 & 0.933 \\
\hline
\end{tabular}


difference that shows that the saturated NHC backbone of the SIMes ligand facilitates the phosphine dissociation since the $\mathrm{Ru}-\mathrm{P}$ bond distance is longer [24,38]. This is corroborated via the corresponding lower MBO values. More interestingly, the $\mathrm{Ru}-\mathrm{C}_{\mathrm{NHC}}$ bond is much shorter for SIMes, with a corresponding MBOs at least 0.030 larger, being more accentuated for the system with the unsubstituted indenylidene ligand, by 0.041 . This effect is completely in agreement with the trans effect along the $\mathrm{C}_{\mathrm{NHC}}-\mathrm{Ru}-\mathrm{P}$ axis [46]. On the other hand, the analysis of the substituted indenylidene systems 3-6 highlights that these are more difficult to activate since the MBO of the Ru-P is larger by $0.045,0.042,0.060$ and 0.051 , respectively. Overall, despite the unfavourable effect on the activation of the precatalytic species I, the substituted indenylidenes do not affect at all the $14 \mathrm{e}$ species II once generated through phosphine release.

To further understand how substituent sterics affect the indenylidene moieties of catalysts 3-6, steric maps were calculated by means of the SambVca package [47], analyzing the $\% \mathrm{~V}_{\mathrm{Bur}}$ [48]. Taking into account the precatalytic intermediate $\mathbf{I}$, the $\% \mathrm{~V}_{\mathrm{Bur}}$ for the NHC ligand ranges from $30.1 \%$ to $29.8 \%$ and $29.6 \%$ for SIMes-based catalysts $\mathbf{1 , 3}$ and 5, respectively (see Figure 1). The same trend applies to the IMes-based catalysts 2, 4 and $\mathbf{6}$, with $\% \mathrm{~V}_{\text {Bur }}$ values of $30.0 \%, 29.7 \%$ and $29.6 \%$, respectively. On the other hand, as expected since there is similarity in the part bonded to the metal [49], no significant difference in the steric hindrance towards the metal sphere was observed for the indenylidene and any of its derivatives, and the $\% \mathrm{~V}_{\text {Bur }}$ was found identical (see Supporting Information File 1 for steric maps of those ligands).

Table 3 includes the relevant information obtained from the frontier molecular orbitals. From conceptual DFT we reach values for electrophilicity that describe a clear trend from species II that is prone to undergo nucleophilic attack by the entering olefin: the substituted indenylidene catalysts 3-6 exhibit lower electrophilicity, especially when bearing the saturated backbone NHC, systems $\mathbf{3}$ and $\mathbf{5}$. Here the SIMes systems with lower electrophilicity are in perfect harmony with higher chemical hardness values [50], and the natural population analysis (NPA) on the $\mathrm{C}_{\text {ylidene }}$ confirms the more positive charge, which might favour the nucleophilic interaction with an olefin.

The NPA charges on ruthenium are not affected by the increase of steric hindrance on the phenyl rings of the indenylidene ligand, and only the IMes ligand shows a small decrease of the charge on the metal centre, on the precatalytic species I. Whereas II must be excluded from the discussion since there is a hydrogen bond $(\mathrm{Ru} \cdots \mathrm{H})$ that affects the charge on the metal, especially strong when the indenylidene is substituted. The $\mathrm{Ru} \cdots \mathrm{H}$ distances for $\mathbf{1}-\mathbf{6}$ are $3.110,3.167,3.004,3.036 \AA$, 2.944, $2.929 \AA$, respectively (see Figure 2). This interaction is due to the rotation of $90^{\circ}$ of the indenylidene ligand. But this $\mathrm{Ru}^{\cdots} \mathrm{H}$ interaction deserves more attention since it is stronger for 3-6 and this in order to reduce the steric repulsion between the substituted phenyl ring of the indenylidene and the close mesityl group of the NHC ligand. One consequence for the more rigid unsaturated IMes systems $\mathbf{4}$ and $\mathbf{6}$ is that the next energy barrier for transition state II-III is larger, since the entering olefin requires a $90^{\circ}$ rotation, and this is partially impeded when the phenyl group is substituted. However, the substituted indenylidene facilitates overcoming the energy barrier of the next transition state, the closure of the metallacycle in order to reduce the steric hindrance. Particularly, the latter transition state is $3.2 \mathrm{kcal} / \mathrm{mol}$ lower in energy for $\mathbf{5}$, whereas only $0.7 \mathrm{kcal} / \mathrm{mol}$ more stable for $\mathbf{1}$. And thermody-

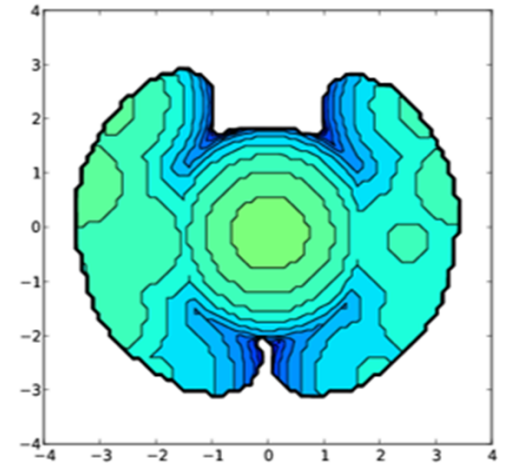

a) $30.1 \%$

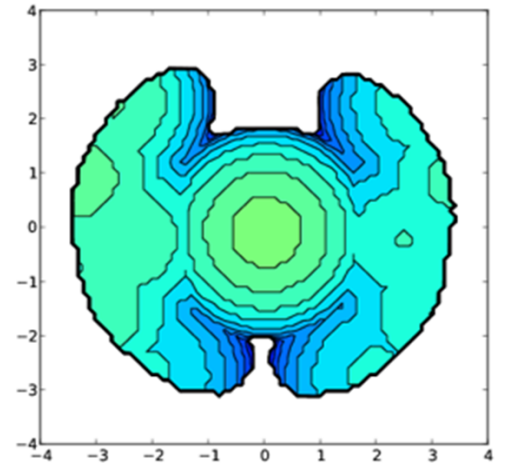

b) $29.8 \%$

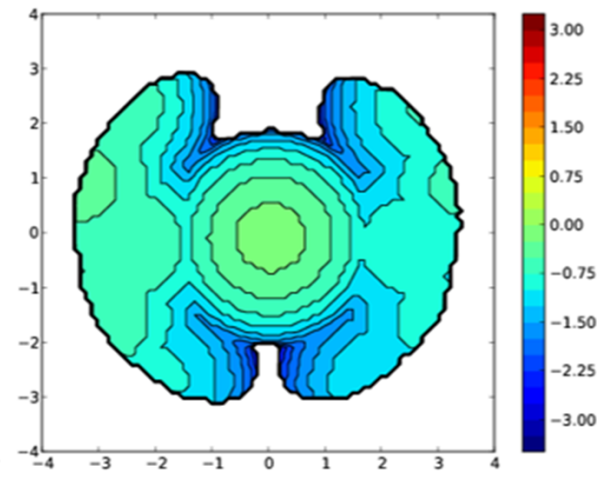

c) $29.6 \%$

Figure 1: Topographic steric maps (plane xy) of the NHC ligands of species I for the studied SIMes-Ru complexes 1, 3 and $\mathbf{5}$, with a radius $3.5 \AA$. $\% V_{\mathrm{Bur}}$ is the percent of buried volume. The Ru atom is at the origin and the Ru-C $\mathrm{NHC}_{\mathrm{NC}}$ bond is aligned with the $z$-axis, and the $\mathrm{Ru}-\mathrm{C}_{\mathrm{ylidene}}$ with the $x$-axis. The isocontour curves of the steric maps are given in $\AA$. 
Table 3: Electronic analysis for species I-III for catalysts 1-6 (in kcal/mol) including energies of the frontier molecular orbitals (HOMO and LUMO); conceptual DFT parameters such as chemical hardness and electrophilicity; and natural population analysis (NPA) charges on ruthenium and ylidenic carbon.

\begin{tabular}{|c|c|c|c|c|c|c|}
\hline & 1 & 2 & 3 & 4 & 5 & 6 \\
\hline \multicolumn{7}{|c|}{ HOMO } \\
\hline I & -0.142 & -0.143 & -0.146 & -0.145 & -0.147 & -0.147 \\
\hline II & -0.168 & -0.162 & -0.169 & -0.162 & -0.168 & -0.161 \\
\hline III & -0.149 & -0.150 & -0.152 & -0.152 & -0.152 & -0.152 \\
\hline \multicolumn{7}{|c|}{ LUMO } \\
\hline I & -0.121 & -0.121 & -0.119 & -0.119 & -0.118 & -0.119 \\
\hline II & -0.127 & -0.127 & -0.125 & -0.125 & -0.125 & -0.125 \\
\hline III & -0.122 & -0.123 & -0.120 & -0.121 & -0.119 & -0.120 \\
\hline \multicolumn{7}{|c|}{ chemical hardness } \\
\hline I & 0.011 & 0.011 & 0.014 & 0.013 & 0.014 & 0.014 \\
\hline II & 0.021 & 0.018 & 0.022 & 0.019 & 0.022 & 0.018 \\
\hline III & 0.014 & 0.013 & 0.016 & 0.015 & 0.016 & 0.016 \\
\hline \multicolumn{7}{|c|}{ electrophilicity } \\
\hline I & 0.788 & 0.784 & 0.642 & 0.663 & 0.611 & 0.629 \\
\hline II & 0.526 & 0.593 & 0.491 & 0.545 & 0.499 & 0.557 \\
\hline III & 0.676 & 0.694 & 0.588 & 0.602 & 0.560 & 0.575 \\
\hline \multicolumn{7}{|c|}{$q(R u)$} \\
\hline I & -0.414 & -0.434 & -0.414 & -0.430 & -0.416 & -0.431 \\
\hline II & -0.101 & -0.100 & -0.099 & -0.110 & -0.119 & -0.121 \\
\hline III & -0.259 & -0.265 & -0.256 & -0.263 & -0.260 & -0.258 \\
\hline \multicolumn{7}{|c|}{$\mathrm{q}\left(\mathrm{C}_{\text {ylidene }}\right)$} \\
\hline I & 0.126 & 0.126 & 0.127 & 0.129 & 0.125 & 0.127 \\
\hline II & 0.098 & 0.094 & 0.101 & 0.104 & 0.110 & 0.109 \\
\hline III & 0.130 & 0.134 & 0.136 & 0.139 & 0.139 & 0.139 \\
\hline
\end{tabular}

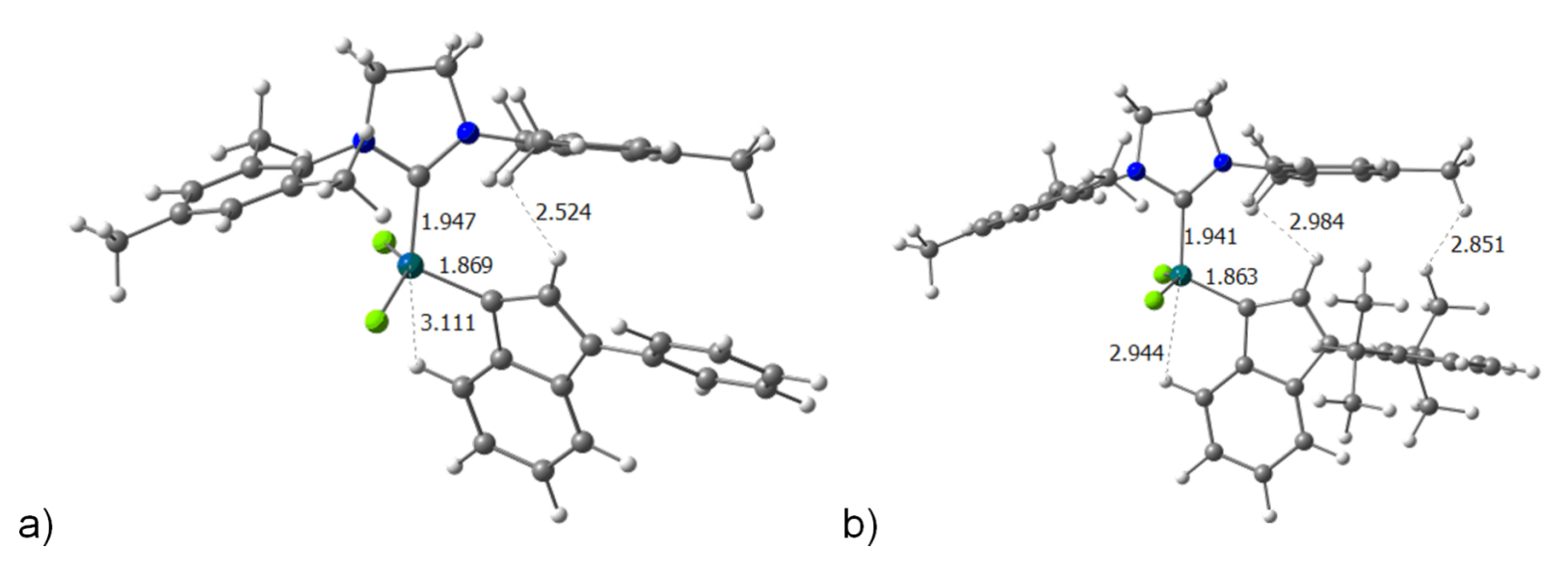

Figure 2: Intermediate II for catalysts a) $\mathbf{1}$ and b) $\mathbf{5}$ (important bond lengths are given in $\AA$ ).

namically, the next metallacycle IV is also favoured with the indenylidene substitution, being 4.2 and $3.4 \mathrm{kcal} / \mathrm{mol}$ relatively more stable for systems $\mathbf{3}$ and $\mathbf{5}$, respectively, with respect to $\mathbf{1}$. This effect of reducing steric hindrance between the ylidene and the NHC ligands was examined previously, with the exchange of benzylidene by indenylidene [51]; and with larger NHC ligands [52].

In order to evaluate the change of the aromaticity of the phenyl ring of the indenylidene derivatives 3-6, we evaluated the 
aromaticity of the six-membered aryl rings, as well as the ring current on the five-membered ring by means of magnetic-based aromaticity criterion NICS (GIAO, see all NICS values in Supporting Information File 1). The 5-membered rings turn out to be non-aromatic, whereas the changes of the aromaticity of the phenyl rings are minimal. Species $\mathbf{I}, \mathbf{2}$ and $\mathbf{3}$ are 0.151 and $0.083 \mathrm{ppm}$ more aromatic than $\mathbf{1}$, nearly identical for the IMes systems $\mathbf{5}$ and $\mathbf{6}, 0.166$ and $1.117 \mathrm{ppm}$ and more aromatic than 4. Once the phosphine has been dissociated, intermediate II becomes roughly $0.5 \mathrm{ppm}$ more aromatic, but the trend for catalysts $\mathbf{1}-\mathbf{6}$ is rather similar, being that 3-6 are approximately $0.1 \mathrm{ppm}$ more aromatic than the non-substituted indenylidene systems $\mathbf{1}$ and $\mathbf{2}$.

\section{Conclusion}

We have investigated the reaction pathway of a series of Ru-based olefin metathesis catalysts that leads to the methylidene catalytic active species, i.e., the activation of the precatalyst. The indenylidene ligand is substituted by congener ligands with ortho-methyl or isopropyl group on its phenyl ring. It was shown that to describe the reactivity, structural, and electronic parameters must be taken into account. The indenylidene ligands, especially the more sterically demanding, impose higher electrophilicity on the ruthenium centre, but structurally favour the relative stability of the metallacycle in order to reduce the steric hindrance between the mesityl groups of either the SIMes or IMes ligands with the ortho substituents on the phenyl group of the indenylidene.

The steric hindrance of the indenylidene derivatives does not affect the metal centre structurally since the steric maps confirm that the effect is far removed from the metal core where the reactivity with the entering olefin takes place. On the other hand, electronically the effect is rather small, with insignificant changes of the aromaticity in the phenyl ring. However, the $14 \mathrm{e}$ species that will accommodate the entering olefin in the next reaction step imposes a stronger $\mathrm{Ru} \cdots \mathrm{H}$ interaction thanks to the substituents on the indenylidene pushing downward the indenylidene ligand itself, to minimise the steric hindrance with the NHC ligand.

\section{Computational Details}

DFT static calculations were performed with the Gaussian 09 set of programs [53], using the BP86 functional of Becke and Perdew [54-56]. The electronic configuration of the molecular systems was described with the double- $\zeta$ basis set with polarisation of Ahlrichs for main group atoms (SVP keyword in Gaussian) [57], whereas for ruthenium the small-core quasirelativistic Stuttgart/Dresden effective core potential, with an associated valence basis set (standard SDD keywords in Gaussian 09), was employed [58-60]. The geometry optimisa- tions were performed without symmetry constraints. Analytical frequency calculations were performed to characterise the located stationary points, apart from calculating the unscaled zeropoint energies (ZPEs) and the thermal corrections and entropy effects at $298 \mathrm{~K}$, and all values at a pressure of 1354 atm using the approach of Martin and co-workers [61], excluding the potential overestimation of the entropy contribution $[38,62,63]$. Energies were obtained by single point calculations on the optimised geometries with the M06 functional [64] and the TZVP basis set [65], and solvent effects were estimated with the polarisable continuous solvation model PCM using dichloromethane as solvent $[66,67]$. The reported free energies in this work include energies obtained at the M06/TZVP sdd level of theory corrected with zero-point energies, thermal corrections, and entropy effects evaluated at $298 \mathrm{~K}$, achieved at the BP86/SVP sdd level. This computational approach for olefin metathesis with $\mathrm{Ru}$ based catalysts turned out to display errors of less than $1 \mathrm{kcal} / \mathrm{mol}$ by Poater and co-workers [68].

The percent buried volume calculations were performed with the SambVca package developed by Cavallo et al. [42]. The radius of the sphere around the origin placed $2 \AA$ below the metal centre was set to $3.5 \AA$, while for the atoms, we adopted the Bondi radii scaled by 1.17 , and a mesh of $0.1 \AA$ was used to scan the sphere for buried voxels. The steric maps were generated also with the SambVca package [69].

Aromaticity was evaluated by means of the nucleus independent chemical shift (NICS) [70,71], proposed by Schleyer et al., as a magnetic descriptor of aromaticity. NICS is defined as the negative value of the absolute shielding computed at a ring centre or at some other interesting point of the system. The more negative the NICS the higher the aromaticity of the ring is considered. NICS values were computed using the gauge-including atomic orbital method (GIAO), at the BP86/SVP level. The magnetic shielding tensor was calculated for ghost atoms located at the centre of the rings determined by the nonweighted mean of the heavy atom coordinates.

\section{Supporting Information}

\section{Supporting Information File 1}

All Cartesian coordinates, 3D view and energies of all species, steric maps and NICS aromaticity values. [https://www.beilstein-journals.org/bjoc/content/ supplementary/1860-5397-14-275-S1.pdf]

\section{Acknowledgements}

A.P. thanks the Spanish MINECO for a project CTQ201459832-JIN, and EU for a FEDER fund (UNGI08-4E-003). 
S.P.N. thanks King Saud University and King Abdullah University of Science and Technology (Award No. OSR-2015-CCF1974-03) for support.

\section{ORCID ${ }^{\circledR}$ iDs}

Steven P. Nolan - https://orcid.org/0000-0001-9024-2035

Luigi Cavallo - https://orcid.org/0000-0002-1398-338X

Albert Poater - https://orcid.org/0000-0002-8997-2599

\section{References}

1. Trnka, T. M.; Grubbs, R. H. Acc. Chem. Res. 2001, 34, 18-29. doi:10.1021/ar000114f

2. Heckelsberg, L. F.; Banks, R. L.; Bailey, G. C. Ind. Eng. Chem. Prod. Res. Dev. 1968, 7, 29-31. doi:10.1021/i360025a007

3. Reuben, B.; Wittcoff, H. J. Chem. Educ. 1988, 65, 605-607. doi:10.1021/ed065p605

4. Lutz, E. F. J. Chem. Educ. 1986, 63, 202-203. doi:10.1021/ed063p202

5. Buchmeiser, M. R. Chem. Rev. 2000, 100, 1565-1604. doi:10.1021/cr990248a

6. Rosebrugh, L. E.; Ahmed, T. S.; Marx, V. M.; Hartung, J.; Liu, P.; López, J. G.; Houk, K. N.; Grubbs, R. H. J. Am. Chem. Soc. 2016, 138, 1394-1405. doi:10.1021/jacs.5b12277

7. Scholl, M.; Ding, S.; Lee, C. W.; Grubbs, R. H. Org. Lett. 1999, 1, 953-956. doi:10.1021/ol990909q

8. Schrock, R. R. Tetrahedron 1999, 55, 8141-8153. doi:10.1016/s0040-4020(99)00304-X

9. Hérisson, J.-L.; Chauvin, Y. Makromol. Chem. 1971, 141, 161-176. doi:10.1002/macp.1971.021410112

10. Perfetto, A.; Costabile, C.; Longo, P.; Grisi, F. Organometallics 2014, 33, 2747-2759. doi:10.1021/om5001452

11. Poater, A.; Solans-Monfort, X.; Clot, E.; Copéret, C.; Eisenstein, O. Dalton Trans. 2006, 3077-3087. doi:10.1039/b604481f

12. Castarlenas, R.; Esteruelas, M. A.; Oñate, E. Organometallics 2005, 24, 4343-4346. doi:10.1021/om050569e

13. Poater, A.; Chaitanya Vummaleti, S. V.; Pump, E.; Cavallo, L. Dalton Trans. 2014, 43, 11216-11220. doi:10.1039/c4dt00325j

14. de Brito Sá, É.; Rodríguez-Santiago, L.; Sodupe, M.; Solans-Monfort, X. Organometallics 2016, 35, 3914-3923. doi:10.1021/acs.organomet.6b00641

15. Aeilts, S. L.; Cefalo, D. R.; Bonitatebus, P. J., Jr.; Houser, J. H.; Hoveyda, A. H.; Schrock, R. R. Angew. Chem. 2001, 113, 1500-1504. doi:10.1002/1521-3757(20010417)113:8<1500::aid-ange1500>3.0.co;2 -i

16. Samojłowicz, C.; Bieniek, M.; Grela, K. Chem. Rev. 2009, 109, 3708-3742. doi:10.1021/cr800524f

17. Schmid, T. E.; Bantreil, X.; Citadelle, C. A.; Slawin, A. M. Z.; Cazin, C. S. J. Chem. Commun. 2011, 47, 7060-7062. doi:10.1039/c1cc10825e

18. Leitgeb, A.; Abbas, M.; Fischer, R. C.; Poater, A.; Cavallo, L.; Slugovc, C. Catal. Sci. Technol. 2012, 2, 1640-1643. doi:10.1039/c2cy20311a

19. Clavier, H.; Caijo, F.; Borré, E.; Rix, D.; Boeda, F.; Nolan, S. P.; Mauduit, M. Eur. J. Org. Chem. 2009, 4254-4265. doi:10.1002/ejoc.200900407

20. Boeda, F.; Clavier, H.; Nolan, S. P. Chem. Commun. 2008, 2726-2740. doi:10.1039/b718287b
21. Lozano-Vila, A. M.; Monsaert, S.; Bajek, A.; Verpoort, F. Chem. Rev. 2010, 110, 4865-4909. doi:10.1021/cr900346r

22. Diesendruck, C. E.; Tzur, E.; Lemcoff, N. G. Eur. J. Inorg. Chem. 2009, 4185-4203. doi:10.1002/ejic.200900526

23. Fürstner, A. Angew. Chem., Int. Ed. 2000, 39, 3012-3043. doi:10.1002/1521-3773(20000901)39:17<3012::aid-anie3012>3.0.co;2g

24. Vougioukalakis, G. C.; Grubbs, R. H. Chem. Rev. 2010, 110, 1746-1787. doi:10.1021/cr9002424

25. Clavier, H.; Grela, K.; Kirschning, A.; Mauduit, M.; Nolan, S. P. Angew. Chem., Int. Ed. 2007, 46, 6786-6801. doi:10.1002/anie.200605099

26. Rouen, M.; Queval, P.; Borré, E.; Falivene, L.; Poater, A.; Berthod, M.; Hugues, F.; Cavallo, L.; Baslé, O.; Olivier-Bourbigou, H.; Mauduit, M. ACS Catal. 2016, 6, 7970-7976. doi:10.1021/acscatal.6b01428

27. Poater, A.; Bahri-Laleh, N.; Cavallo, L. Chem. Commun. 2011, 47, 6674-6676. doi:10.1039/c1cc11594d

28. Manzini, S.; Nelson, D. J.; Lebl, T.; Poater, A.; Cavallo, L.; Slawin, A. M. Z.; Nolan, S. P. Chem. Commun. 2014, 50, 2205-2207. doi:10.1039/c3cc49481k

29. Martínez, J. P.; Vummaleti, S. V. C.; Falivene, L.; Nolan, S. P.; Cavallo, L.; Solà, M.; Poater, A. Chem. - Eur. J. 2016, 22, 6617-6623. doi:10.1002/chem.201600383

30. Poater, A.; Credendino, R.; Slugovc, C.; Cavallo, L. Dalton Trans. 2013, 42, 7271-7275. doi:10.1039/c3dt32884h

31. Arnedo, L.; Chauvin, R.; Poater, A. Catalysts 2017, 7, 85. doi:10.3390/catal7030085

32. Credendino, R.; Poater, A.; Ragone, F.; Cavallo, L. Catal. Sci. Technol. 2011, 1, 1287-1297. doi:10.1039/c1cy00052g

33. Manzini, S.; Urbina Blanco, C. A.; Nelson, D. J.; Poater, A.; Lebl, T.; Meiries, S.; Slawin, A. M. Z.; Falivene, L.; Cavallo, L.; Nolan, S. P. J. Organomet. Chem. 2015, 780, 43-48. doi:10.1016/j.jorganchem.2014.12.040

34. Jafarpour, L.; Schanz, H.-J.; Stevens, E. D.; Nolan, S. P. Organometallics 1999, 18, 5416-5419. doi:10.1021/om990587u

35. Pump, E.; Slugovc, C.; Cavallo, L.; Poater, A. Organometallics 2015, 34, 3107-3111. doi:10.1021/om501246q

36. Bantreil, X.; Poater, A.; Urbina-Blanco, C. A.; Bidal, Y. D.; Falivene, L.; Randall, R. A. M.; Cavallo, L.; Slawin, A. M. Z.; Cazin, C. S. J. Organometallics 2012, 31, 7415-7426. doi:10.1021/om300703p

37. Manzini, S.; Urbina-Blanco, C. A.; Poater, A.; Slawin, A. M. Z.; Cavallo, L.; Nolan, S. P. Angew. Chem., Int. Ed. 2012, 51, 1042-1045. doi:10.1002/anie.201106915

38. Manzini, S.; Poater, A.; Nelson, D. J.; Cavallo, L.; Slawin, A. M. Z.; Nolan, S. P. Angew. Chem., Int. Ed. 2014, 53, 8995-8999. doi:10.1002/anie.201403770

39. Urbina-Blanco, C. A.; Poater, A.; Lebl, T.; Manzini, S.; Slawin, A. M. Z.; Cavallo, L.; Nolan, S. P. J. Am. Chem. Soc. 2013, 135, 7073-7079. doi:10.1021/ja402700p

40. Poater, A.; Pump, E.; Vummaleti, S. V. C.; Cavallo, L. Chem. Phys. Lett. 2014, 610-611, 29-32. doi:10.1016/j.cplett.2014.06.063

41. Luque-Urrutia, J. A.; Gimferrer, M.; Casals-Cruañas, Ė.; Poater, A. Catalysts 2017, 7, 389. doi:10.3390/catal7120389

42. Poater, A.; Cavallo, L. Beilstein J. Org. Chem. 2015, 11, 1767-1780. doi:10.3762/bjoc.11.192

43. Wappel, J.; Fischer, R. C.; Cavallo, L.; Slugovc, C.; Poater, A. Beilstein J. Org. Chem. 2016, 12, 154-165. doi:10.3762/bjoc.12.17

44. Mayer, I. Chem. Phys. Lett. 1983, 97, 270-274. doi:10.1016/0009-2614(83)80005-0 
45. Mayer, I. Int. J. Quantum Chem. 1984, 26, 151-154. doi:10.1002/qua.560260111

46. Vummaleti, S. V. C.; Nelson, D. J.; Poater, A.; Gómez-Suárez, A.; Cordes, D. B.; Slawin, A. M. Z.; Nolan, S. P.; Cavallo, L. Chem. Sci. 2015, 6, 1895-1904. doi:10.1039/c4sc03264k

47. Falivene, L.; Credendino, R.; Poater, A.; Petta, A.; Serra, L.; Oliva, R.; Scarano, V.; Cavallo, L. Organometallics 2016, 35, 2286-2293. doi:10.1021/acs.organomet.6b00371

48. Poater, A.; Cosenza, B.; Correa, A.; Giudice, S.; Ragone, F.; Scarano, V.; Cavallo, L. Eur. J. Inorg. Chem. 2009, 1759-1766. doi:10.1002/ejic.200801160

49. Lamberti, M.; Fortman, G. C.; Poater, A.; Broggi, J.; Slawin, A. M. Z.; Cavallo, L.; Nolan, S. P. Organometallics 2012, 31, 756-767. doi:10.1021/om2012425

50. Poater, A.; Saliner, A. G.; Carbó-Dorca, R.; Poater, J.; Solà, M.; Cavallo, L.; Worth, A. P. J. Comput. Chem. 2009, 30, 275-284. doi:10.1002/jcc.21041

51. Poater, A.; Ragone, F.; Correa, A.; Cavallo, L. Dalton Trans. 2011, 40, 11066-11069. doi:10.1039/c1dt10959f

52. Poater, A.; Falivene, L.; Urbina-Blanco, C. A.; Manzini, S.; Nolan, S. P.; Cavallo, L. Dalton Trans. 2013, 42, 7433-7439. doi:10.1039/c3dt32980a

53. Gaussian 09, Revision E.01; Gaussian, Inc.: Wallingford, CT, 2009.

54. Becke, A. D. Phys. Rev. A: At., Mol., Opt. Phys. 1988, 38, 3098-3100. doi:10.1103/physreva.38.3098

55. Perdew, J. P. Phys. Rev. B: Condens. Matter Mater. Phys. 1986, 33 , 8822-8824. doi:10.1103/physrevb.33.8822

56. Perdew, J. P. Phys. Rev. B 1986, 34, 7406. doi:10.1103/physrevb.34.7406

57. Schäfer, A.; Horn, H.; Ahlrichs, R. J. Chem. Phys. 1992, 97, 2571-2577. doi:10.1063/1.463096

58. Häussermann, U.; Dolg, M.; Stoll, H.; Preuss, H.; Schwerdtfeger, P.; Pitzer, R. M. Mol. Phys. 1993, 78, 1211-1224. doi:10.1080/00268979300100801

59. Küchle, W.; Dolg, M.; Stoll, H.; Preuss, H. J. Chem. Phys. 1994, 100, 7535-7542. doi:10.1063/1.466847

60. Leininger, T.; Nicklass, A.; Stoll, H.; Dolg, M.; Schwerdtfeger, P. J. Chem. Phys. 1996, 105, 1052-1059. doi:10.1063/1.471950

61. Martin, R. L.; Hay, P. J.; Pratt, L. R. J. Phys. Chem. A 1998, 102, 3565-3573. doi:10.1021/jp980229p

62. Falivene, L.; Barone, V.; Talarico, G. Mol. Catal. 2018, 452, 138-144. doi:10.1016/j.mcat.2018.04.012

63. Luque-Urrutia, J. A.; Poater, A. Inorg. Chem. 2017, 56, 14383-14387. doi:10.1021/acs.inorgchem.7b02630

64. Zhao, Y.; Truhlar, D. G. Theor. Chem. Acc. 2008, 120, 215-241. doi:10.1007/s00214-007-0310-x

65. Schäfer, A.; Huber, C.; Ahlrichs, R. J. Chem. Phys. 1994, 100, 5829-5835. doi:10.1063/1.467146

66. Barone, V.; Cossi, M. J. Phys. Chem. A 1998, 102, 1995-2001. doi:10.1021/jp9716997

67. Tomasi, J.; Persico, M. Chem. Rev. 1994, 94, 2027-2094. doi:10.1021/cr00031a013

68. Poater, A.; Pump, E.; Vummaleti, S. V. C.; Cavallo, L. J. Chem. Theory Comput. 2014, 10, 4442-4448. doi:10.1021/ct5003863

69. Jacobsen, H.; Correa, A.; Poater, A.; Costabile, C.; Cavallo, L. Coord. Chem. Rev. 2009, 253, 687-703. doi:10.1016/j.ccr.2008.06.006

70. Schleyer, P. v. R.; Maerker, C.; Dransfeld, A.; Jiao, H.; van Eikema Hommes, N. J. R. J. Am. Chem. Soc. 1996, 118, 6317-6318. doi:10.1021/ja960582d
71. Chen, Z.; Wannere, C. S.; Corminboeuf, C.; Puchta, R.; Schleyer, P. v. R. Chem. Rev. 2005, 105, 3842-3888. doi:10.1021/cr030088+

\section{License and Terms}

This is an Open Access article under the terms of the Creative Commons Attribution License (http://creativecommons.org/licenses/by/4.0). Please note that the reuse, redistribution and reproduction in particular requires that the authors and source are credited.

The license is subject to the Beilstein Journal of Organic Chemistry terms and conditions:

(https://www.beilstein-journals.org/bjoc)

The definitive version of this article is the electronic one which can be found at:

doi:10.3762/bjoc. 14.275 